\title{
Engagement and Performance Studies of Media Agencies Publications on Social Networks
}

\author{
https://doi.org/10.3991/ijes.v8i3.16949 \\ Mohcine Kodad \\ Mohammed First University, Oujda, Morocco \\ mohcine. kodadegmail. com
}

\begin{abstract}
This paper presents a study that contributes to the existing work on the social diffusion and interaction strategy in social media. The aim is to know the most shared post by some electronic media in the world from end to end social network, and also to know post nature of the most successful one, and the link between different kind of interaction these are main objectives of this study. Our work is also considered as a ground and a base for social network analysis researchers in all social networks in order to allow them to benefit and help in their future research work from all information collected and results found via this study. An empirical analysis using multiple methods is conducted based on 275 Facebook publications gathered from the Facebook pages of 5 electronics journals the best one in its original country represented 5 countries in the world. This contribution discovered a set of important information and it is also projected to confirm hypothesis addressed in pre-existing studies.
\end{abstract}

Keywords-Social network, Posts, Facebook, Interaction.

\section{$1 \quad$ Introduction}

Since the advent of web 2.0, internet users have taken control of all the uses, tools and features of the web that now allow them to contribute easily to promote exchange of information and make interaction (discuss, share, exchange, etc.) in a simple and easy way, both with the content published on the internet but also between them, thus creating a new web said social media or social network. On the other hand, social networks cover different activities that integrate technology, social interaction (between individuals or groups of individuals), and creation of content. Social networks consider themselves as a group of online applications (blogs, micro blogs, sharing sites, social networks, etc.) that are based on Web technology, we talk here about participatory web, social web and collective intelligence [1] and allow creating and exchange the content generated by users.

This web evolution has made it possible to build different types of large social networks, which are now recognized as an important means to share information [2]. Social network is a social media that concern different social relationships between individuals and the way that they are structured; these different relationships help to understand the behavior of individuals [11]. Thus, it is represented by a well-defined structure 
with a dynamic form of a social group creates "fans", "followers", "friends" or "contacts" according to communities of interest of its own.

Currently social networks are used almost everywhere, at home, at school, at work and available at any platform computer, Smartphone, tablet, etc. it plays a very important role in the individual's life, with its benefits and its disadvantages according to the way it is used [3].

Among many Social network available, Facebook has been the most popular social networks worldwide with 2234 million active users [4] which account for 54\% of total worldwide Internet users [5]. Facebook is intentionally designed for all users in the internet to connect with their friend or family to keep in touch with acquaintances, and to develop all connections with new people through features offered. Interestingly, although Facebook is the third popular Website globally following Google and YouTube, it is the fourth popular Website in Morocco according to Alexa.com [6]. Facebook was initially intended to be used only by students at Harvard University before it opened up as a social network to the public in Spring 2017 [7]. This web site had more than 845 million active users as of February 2012 [8].

Some researchers have tested how Facebook is attached to different aspects of the student experience including learning [12][22][23][24][28], student engagement [29] multitasking [14][25], political activity [30], political participation [16], development of identity and peer relationships [17], and relationship building and maintenance [18], security [19], behaviors study [20], optimization and influence diffusion[13][15] and many other fields. Furthermore, researchers have tested how Facebook use relates to personality variables such as scores on big five personality scope; honesty, meticulousness, extraversion, friendliness, and neuroticism [21][26][27], and some approach to analyze user-generated comments from social media like [31].

Given that the Facebook is still the leader social media in the world in terms of usage so far, that's why our work will focus on this social network. The main objective of this paper is to study the interactions of social networks users, in order to identify any useful information and to understand the behavior of users towards publications posted and for another hand to know the type of publication the most shared in a set of Facebook pages that represent 5 countries (Morocco, Spain, France, United Kingdom and USA).

Since the intermediary between users and Facebook pages are publications. this leads us to ask a number of questions, starting with what is published by the media agencies? What kind of publications the most published? the most shared? what is its nature? which is the most attractive? etc. In [9] they are talking that the posts including links are more likely to generate higher levels of brand post popularity. So, we will try to answer to these issues in this paper being organized as follow: in the section 2 we talk about a detailed experimental methodology used, the data analysis and results are mentioned in the section 3 and we conclude this paper with some perspectives in the section 4. Note that the word "Like" talking about in all paragraphs of this paper, represents the set of Empathy Buttons that Facebook offers. 


\section{Experimental Methodology}

Facebook is an online social network that allows its users to publish "status", "photo", "video" or "link", and to share "files" or "documents" in groups that it offers. It is also a space for exchanging messages, to join and create pages and to use the set of applications circulating in this famous social network.

For its posts publishing strategy, it uses the algorithm called Edge Rank which aims is to choose and to order the content appearing on the news feed of users [10], the principle of this algorithm is very simple: for each user and each content, the goal is to define a score of relevance, which will classify the different messages and display the best. The score is calculated according to three parameters, which we will note A, T and $\mathrm{F}$.

- A: Is the affinity, which measures how the user and the author of the content are close.

- T: Is a measure of attractiveness of the content (more for photos than for texts for example).

- F: Is the freshness, weak if the content is old, strong if it has just been posted.

The score is the result of multiplication of all parameters:

$$
\text { score }=\mathrm{A} \times \mathrm{T} \times \mathrm{F}
$$

To go deeper in our experience we have chosen five existing Facebook pages (B, C, E, $\mathrm{H}$ and $\mathrm{M}$ ) which represent respectively five countries (United Kingdom, USA, Spain, Morocco and France), we talk about the official Facebook pages of the most famous media platforms in their original countries and having a number of fans that exceed 4 million one. Then, we extracted all the necessary data concerning their publications posted during Wednesday 02/05/2018, and we also collected all the interactions made in this day during 24 hours (number of posts, type of posts, number of comments, number of shares, and number of interactions via empathy button).

The selected pages are:

- Page B: This is the BBC official Facebook page from UK. In this country, Facebook is ranked in 4th place, according to Alexa (Data extracted on 02/05/2018), the BBC website took in 99th place in the world and in 6th place in United Kingdom. The BBC Facebook page is currently followed by 48,729,688 people (Data retrieved on March 31, 2019).

- Page C: This is the CNN official Facebook page from USA. In this country, Facebook is ranked in third place after Google and YouTube, according to Alexa (Data extracted on 02/05/2018), CNN's website took in 105th place in the world and in 25th place in USA. The CNN Facebook page is currently followed by 31,207,719 people (Data retrieved on March 31, 2019).

- Page E: This is the El Pais official Facebook page from Spain. In this country, Facebook is ranked in 4th place after Google.es, Google.com and YouTube, according to Alexa (Data extracted on 02/05/2018), the El País website took in 409th place in the 
world and in 12th place in Spain. The El Pais Facebook page is currently followed by 4,966,913 people (Data retrieved on March 31, 2019).

- Page H: This is the Hespress official Facebook page from Morocco. In this country, Facebook is ranked in 4th place, according to Alexa (Data extracted on 02/05/2018), the Hespress website took in 648th place in the world, and in 3rd place in Morocco after Google and YouTube. The Hespress Facebook page is currently followed by 14,865,892 people (Data retrieved on March 31, 2019).

- Page M: This is the official Facebook page of "Le Monde" from France. In this country, Facebook is ranked in 4th place after Google.fr, Google.com and YouTube, according to Alexa (Data extracted on 02/05/2018), the website of "Le Monde" took in 712th place in the world and in 21st place in France. The Facebook page "Le Monde" is currently followed by 4,296,639 people (Data retrieved on March 31, 2019).

In this experiment, we did not cite examples of the media platforms of the major economic countries like China and Russia for the simple reason that they have other social networking tools that are used much more than Facebook.

\section{Data Analysis and Results}

\subsection{Data analysis}

We should further recall that the data was extracted in Wednesday, May 02, 2018 from the news feeds by just collecting the publications published in the same day above (and taking into consideration UTC+1 as time zone).

Thus, all data (number of posts, type of posts, number of comments, number of shares, and number of interactions via empathy button) are extracted from the HTML tags that carry the necessary information that we have need:

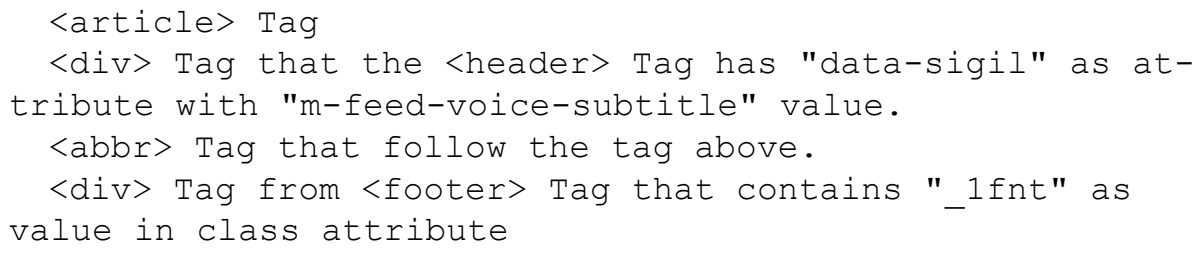

It should be noted that the extract of data from news feed is done manually (nonautomatically). After collecting the data, we found some results that we put it in as form and diagrams come in the following paragraphs.

Figure 1, represents the number of publications published by type and by Facebook page, which are in total 275 (234 as links, 1 as photo, 40 as videos). The figure 2, represents the percentages of all publications posted by type for the five Facebook pages.

Figures 1 and 2 describe the various kinds of publications, and the one that dominates or the most shared on the Facebook pages for these 5 media companies. it is link type publication. 


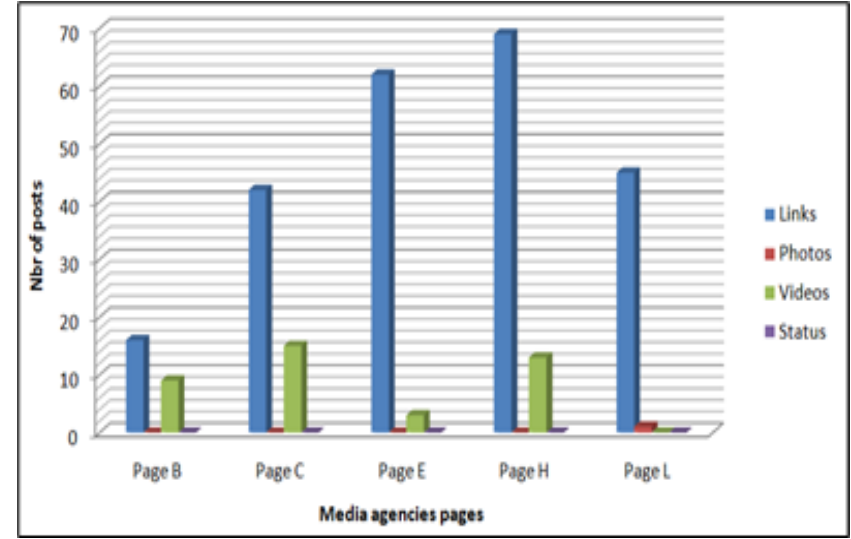

Fig. 1. The number of publications by type and by Facebook page

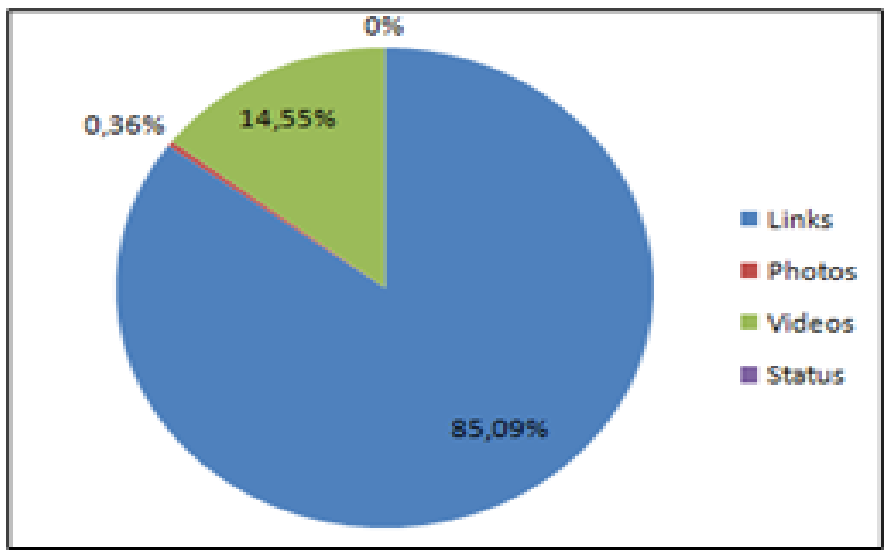

Fig. 2. Percentages of 275 publications by type

Tables 1, 2 and 3 present all the data relating to the pages with all types of interactions performed, since there are 3 types of interaction (Comments, Share, or Likes Buttons).

These tables contain 7 lines, as follows:

- Line - 1) page name: we talk about the name of the page

- Line - 2) number of fans: is the number of fans of each page

- Line - 3) links: here it follows the following algorithm: 


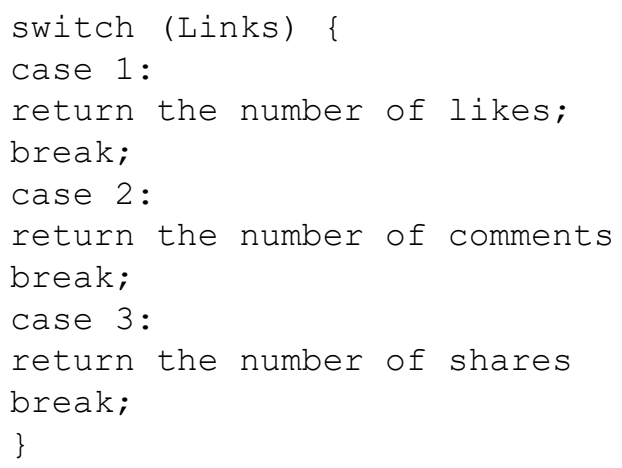

- Line - 4) Videos: the same line 3 process

- Line - 5) Photos: the same line 3 process

- Line - 6) Total of likes or total of comments or total of shares: This is the total number of each type of interaction over to all publications.

- Line - 7) performance rate: is calculated according to this formula:

$$
P R=\frac{\sum \mathrm{Ni}}{\mathrm{NF}}
$$

where:

- PR: Performance Rate

- Ni: the number of interactions for each type (share, comment or likes)

- NF: Number of Fans page

Note: It should be noted that since the status type is not present in data extracted from the content of these five pages, so, it will be excluded in the analysis table.

Case (1): Likes buttons' performance

Table 1. Results Analysis of «Likes Buttons » on posts sharing in Facebook pages

\begin{tabular}{|l|c|c|c|c|c|}
\hline \multicolumn{1}{|c|}{ Page Name } & B & C & E & H & L \\
\hline \multicolumn{1}{|c|}{ Nbr of Fans } & $\mathbf{4 8 7 2 9 6 8 8}$ & $\mathbf{3 1 2 0 7 7 1 9}$ & $\mathbf{4 9 6 6 \mathbf { 9 1 3 }}$ & $\mathbf{1 4 8 6 5 8 9 2}$ & $\mathbf{4 2 9 6 \mathbf { 6 3 9 }}$ \\
\hline Links & 113500 & 212918 & 66703 & 71483 & 15405 \\
Videos & 32281 & 73320 & 8527 & 22392 & 0 \\
Photos & 0 & 0 & 0 & 0 & 911 \\
\hline Total of likes & 145781 & 286238 & 75230 & 93875 & 16316 \\
\hline Performance rate & $0.30 \%$ & $0.92 \%$ & $1.51 \%$ & $0.63 \%$ & $0.38 \%$ \\
\hline
\end{tabular}


Case (2): Comments' performance

Table 2. Results Analysis of «Comments » on posts sharing in Facebook pages

\begin{tabular}{|l|c|c|c|c|c|}
\hline \multicolumn{1}{|c|}{ Page Name } & B & C & E & H & L \\
\hline \multicolumn{1}{|c|}{ Nbr of Fans } & $\mathbf{4 8 7 2 9 ~ 6 8 8}$ & $\mathbf{3 1 2 0 7 7 1 9}$ & $\mathbf{4 9 6 6 \mathbf { 9 1 3 }}$ & $\mathbf{1 4 8 6 5 \mathbf { 8 9 2 }}$ & $\mathbf{4 2 9 6 6 3 9}$ \\
\hline Links & 19471 & 63207 & 7302 & 11359 & 5946 \\
Videos & 9762 & 25385 & 1337 & 4441 & 0 \\
Photos & 0 & 0 & 0 & 0 & 278 \\
\hline Total of Comments & 29233 & 88592 & 8639 & 15800 & 6224 \\
\hline Performance rate & $0.06 \%$ & $0.28 \%$ & $0.17 \%$ & $0.11 \%$ & $0.14 \%$ \\
\hline
\end{tabular}

Case (3): Shares' performance

Table 3. Results Analysis of « Shares » on posts sharing in Facebook pages.

\begin{tabular}{|l|c|c|c|c|c|}
\hline \multicolumn{1}{|c|}{ Page Name } & B & C & E & H & L \\
\hline \multicolumn{1}{|c|}{ Nbr of Fans } & $\mathbf{4 8 7 2 9 ~ 6 8 8}$ & $\mathbf{3 1 2 0 7 7 1 9}$ & $\mathbf{4 9 6 6 9 1 3}$ & $\mathbf{1 4 8 6 5 8 9 2}$ & $\mathbf{4 2 9 6 6 3 9}$ \\
\hline Links & 19455 & 44809 & 19618 & 3015 & 3938 \\
Videos & 14047 & 26441 & 3502 & 4667 & 0 \\
Photos & 0 & 0 & 0 & 0 & 122 \\
\hline Total of Shares & 33502 & 71250 & 23120 & 7682 & 4060 \\
\hline Performance rate & $0.07 \%$ & $0.23 \%$ & $0.47 \%$ & $0.05 \%$ & $0.09 \%$ \\
\hline
\end{tabular}

Figure 3 shows a summary of the performance, which clearly shows that the like button is the most expressive as type of interaction in all publications, and we also see that page $E$ is the most effective of the other pages in term of this rate whether for the rate of performance of like or that of share. while for the rate of performance of the comments page $\mathrm{C}$ remains the leader.

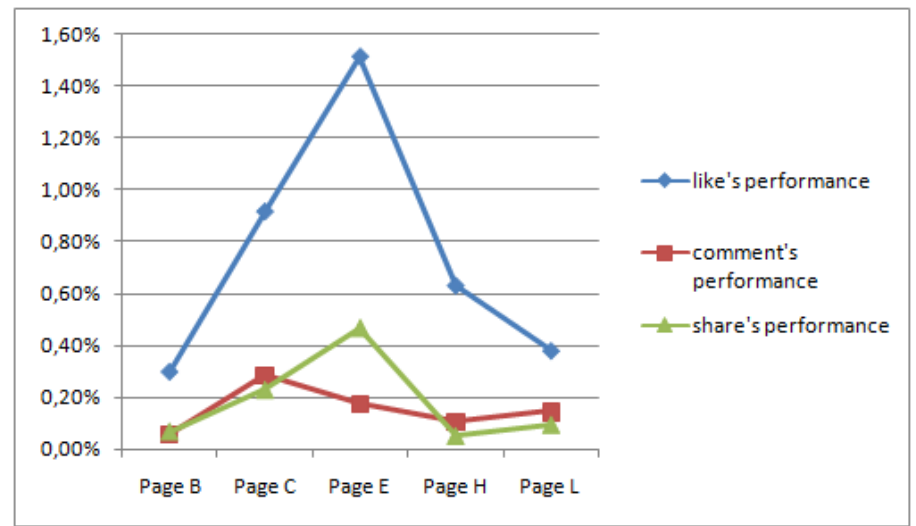

Fig. 3. Performance rate of interaction types over pages B, C, E, H, and L

Table 4 summarizes the number of posts and the type of posts for each page. 
Figures 4, 5, 6, 7 and 8, provide an overview of the number of interactions to publications that are merged and classified per hour over the 24 hours in the day of 02/05/2018.

Table 4. Number of posts by type of each page

\begin{tabular}{|l|c|c|c|c|c|}
\hline & Links & Photos & Videos & Status & Total of Posts \\
\hline Page B & 16 & 0 & 9 & 0 & 25 \\
\hline Page C & 42 & 0 & 15 & 0 & 57 \\
\hline Page E & 62 & 0 & 3 & 0 & 65 \\
\hline Page H & 69 & 0 & 13 & 0 & 82 \\
\hline Page L & 45 & 1 & 0 & 0 & 46 \\
\hline Total & $\mathbf{2 3 4}$ & $\mathbf{1}$ & $\mathbf{4 0}$ & $\mathbf{0}$ & $\mathbf{2 7 5}$ \\
\hline
\end{tabular}

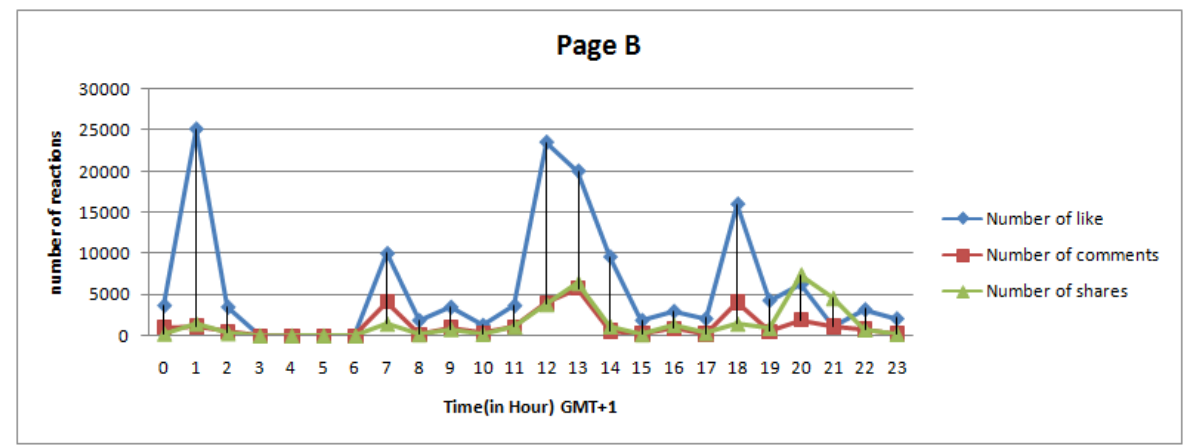

Fig. 4. Number of interactions per publishing hour for page B with 25 posts

For the publications posted on page $\mathrm{B}$ which constitute 25 publications with a total of 208,516 as a number of reactions between (Likes, shares and comments), and according to figure 4 , we see that the reactions increase clearly in 3 periods who take the majority of all reactions.

Period 1; between $00 \mathrm{~h}$ to $02 \mathrm{~h} \mathrm{UTC}+1$ including 4 publications are posted.

Period 2; between $11 \mathrm{~h}$ to $14 \mathrm{~h}$ UTC +1 including 6 publications are posted.

Period 3; between $17 \mathrm{~h}$ to $19 \mathrm{~h}$ UTC +1 including 3 publications are posted.

Since this page is from United Kingdom, suddenly the time used by fans of the page follows UTC+1 as time zone so it keeps the same hours.

For the publications posted on page $\mathrm{C}$ which constitute 57 publications with a total of 446,080 as the number of reactions between (Likes, shares and comments), and according to Figure 5, we see that the reactions increase clearly in 2 periods who take the majority of all reactions.

Period 1 ; between $08 \mathrm{~h}$ to $14 \mathrm{~h}$ with a decrease around $11 \mathrm{~h}$ UTC +1 of which 21 publications are posted.

Period 2; between $19 \mathrm{~h}$ to $23 \mathrm{~h}$ UTC +1 with a drop to $21 \mathrm{~h}$ including 11 publications are posted.

Since this page is from USA, so the time used by the fans of this page follows UTC4 as time zone 


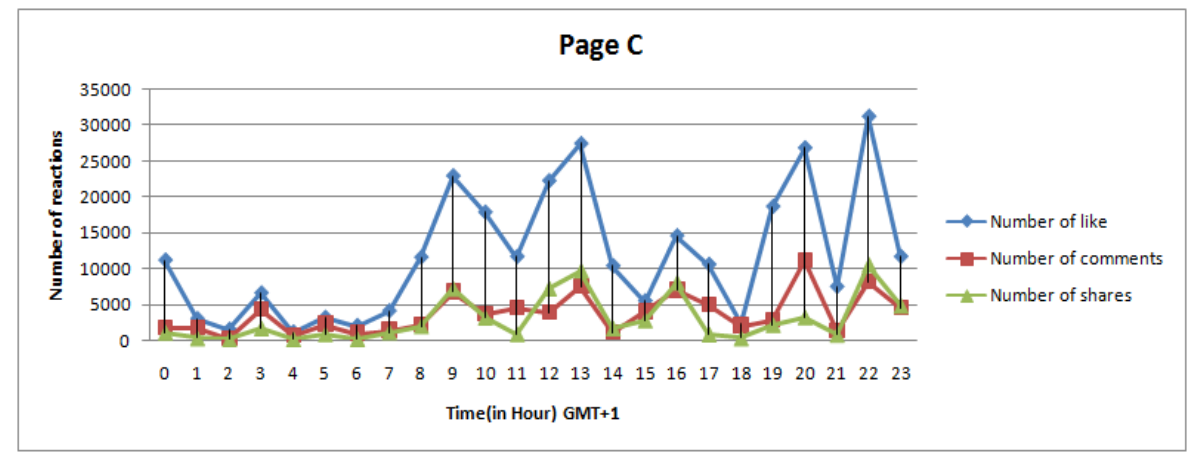

Fig. 5. Number of interactions per publishing hour for page $\mathrm{C}$ with 57 posts

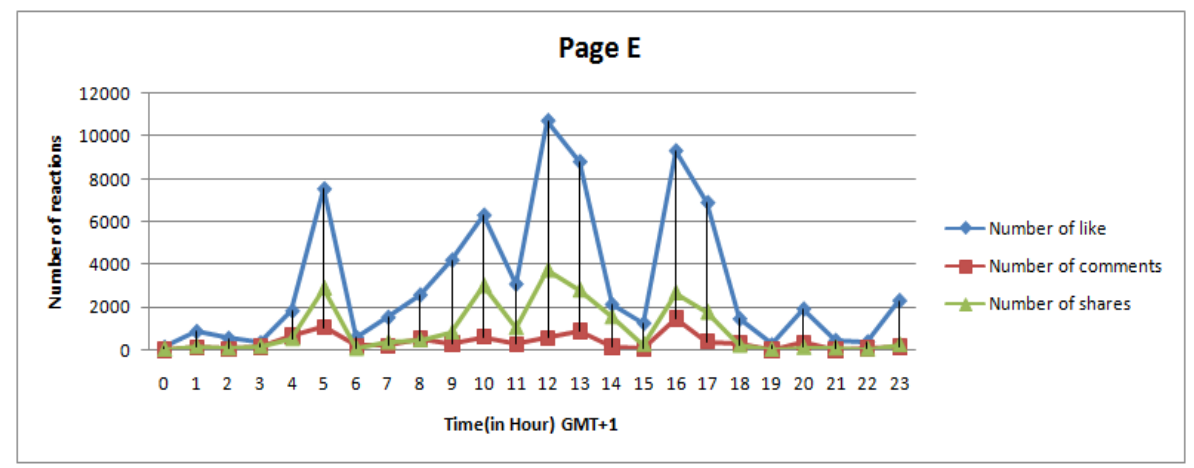

Fig. 6. Number of interactions per publishing hour for page $\mathrm{E}$ with 65 posts

For the publications posted on page $\mathrm{E}$ which constitute 65 publications with a total of 106,989 as the number of reactions between (Likes, shares and comments), and according to figure 6 , we see that the reactions increase clearly in 3 periods who take the majority of all reactions.

Period 1; between $04 \mathrm{~h}$ to $06 \mathrm{~h}$ UTC +1 including 7 publications are posted.

Period 2; between $09 \mathrm{~h}$ to $14 \mathrm{~h}$ UTC +1 with a decrease around $11 \mathrm{~h}$ including 23 publications are posted.

Period 3; between $15 \mathrm{~h}$ to $18 \mathrm{~h}$ UTC +1 of which 17 publications are posted.

Since this page is originally from Spain, suddenly the time used by the fans of the page follows UTC+2 as time zone. 


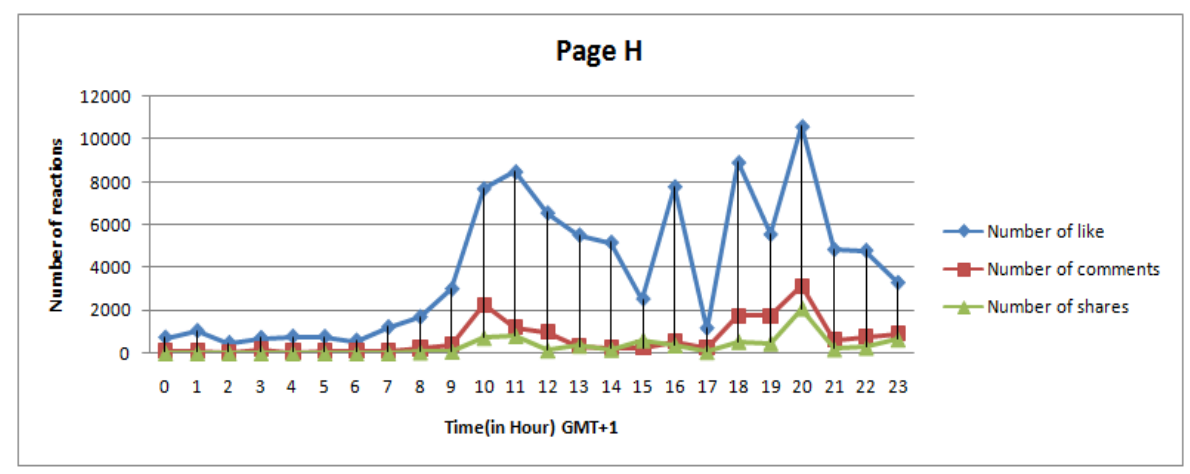

Fig. 7. Number of interactions per publishing hour for page $H$ with 82 posts

For the publications posted in page $\mathrm{H}$ which constitute 82 publications with a total of 117346 as the number of reactions between (Likes, shares and comments), and according to Figure 7, we see that the reactions are clearly increasing in a long period that starts at $9 \mathrm{am}$ and arrives at $23 \mathrm{~h}$ but with a decrease in 2 occasions one around $15 \mathrm{~h}$ $\mathrm{UTC}+1$ and the other around $17 \mathrm{~h} \mathrm{UTC}+1$ which 54 publications are posted in this long period.

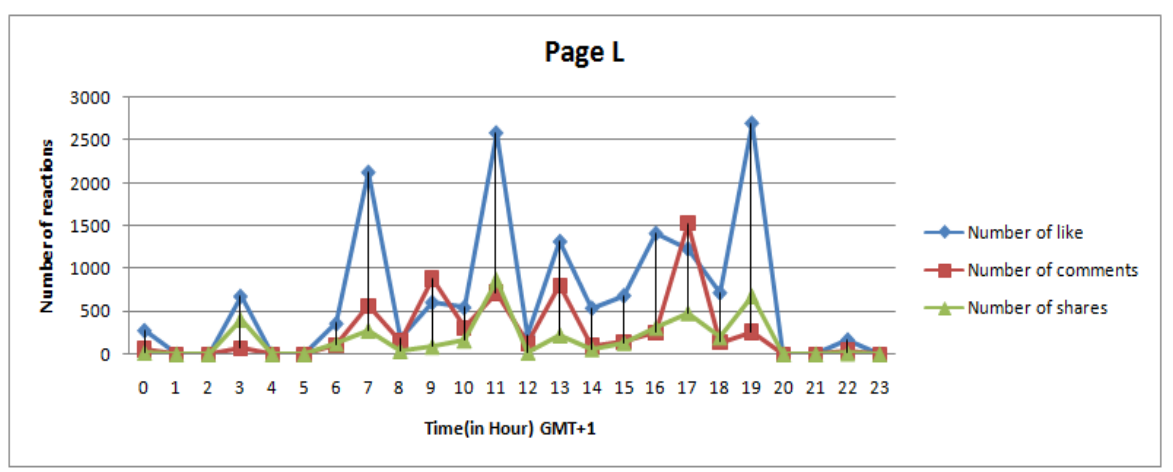

Fig. 8. Number of interactions per publishing hour for page L with 46 posts

Since this page is from Morocco, suddenly the time used by the fans of the page follows the UTC +1 as time zone so it keeps the same hours.

For the publications posted on page $\mathrm{L}$ which constitute 46 publications with a total of 26600 as the number of reactions between (Likes, shares and comments), and according to Figure 8, we see that the reactions increase clearly in 3 periods, who take the majority of all reactions.

Period 1; between $06 \mathrm{~h}$ to $08 \mathrm{~h}$ UTC +1 including 7 publications are posted.

Period 2; between $10 \mathrm{~h}$ to $12 \mathrm{~h}$ UTC +1 including 10 publications are posted.

Period 3; between $18 \mathrm{~h}$ to $20 \mathrm{~h}$ UTC +1 including 6 publications are posted.

Since this page is native to France, suddenly the time used by the fans of the page follows UTC +2 as time zone. 


\subsection{Correlations results}

Here we discuss the subject of correlation, to know its presence between the set of reaction tools (Shares, Comments and likes) for the five pages studied.

The correlation coefficient between two real random variables $\mathrm{X}$ and $\mathrm{Y}$ each having a variance, denoted by Cor $(\mathrm{X}, \mathrm{Y})$. Or sometimes simply $\mathrm{r}$, that is defined by:

$$
r=\frac{\operatorname{Cov}(\mathrm{X}, \mathrm{Y})}{\sigma_{\mathrm{X}} \sigma_{\mathrm{Y}}}
$$

where $\operatorname{Cov}(\mathrm{X}, \mathrm{Y})$ is the covariance of the variables $\mathrm{X}$ and $\mathrm{Y}, \sigma_{\mathrm{X}}$ and $\sigma_{\mathrm{Y}}$ their standard deviations.

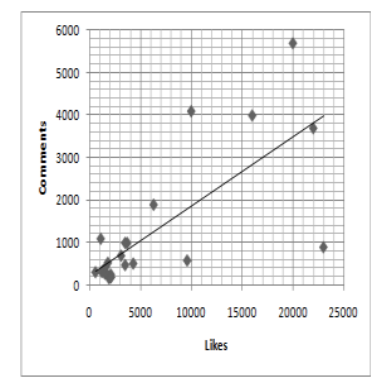

$r=0.7484$

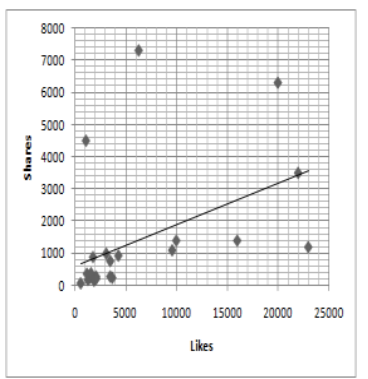

$r=0.4652$

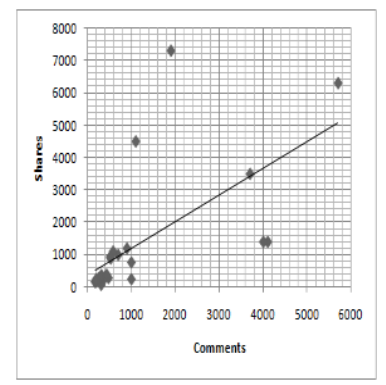

$r=0.6375$

Fig. 9. Correlation Results for Page B

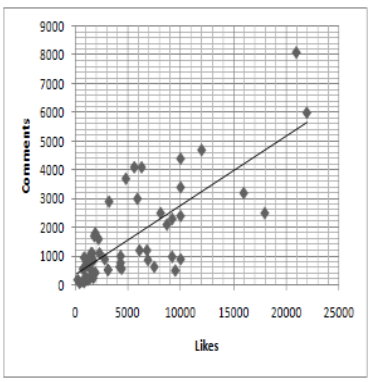

$r=0.7645$

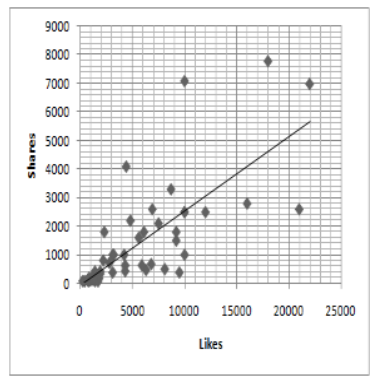

$r=0.7663$

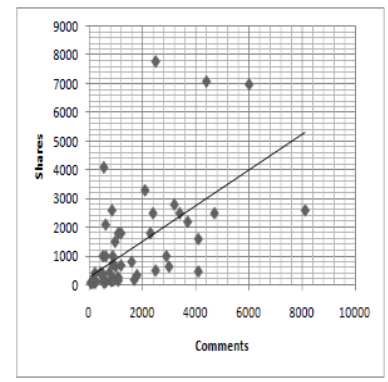

$$
r=0.5802
$$

Fig. 10. Correlation Results for Page $C$

This is the equivalent of:

$$
r=\frac{\mathrm{E}[(\mathrm{X}-\mathrm{E}(\mathrm{X}))(\mathrm{Y}-\mathrm{E}(\mathrm{Y}))]}{\sigma_{\mathrm{X}} \sigma_{\mathrm{Y}}}=\frac{\mathrm{E}(\mathrm{XY})-\mathrm{E}(\mathrm{X}) \mathrm{E}(\mathrm{Y})}{\sigma_{\mathrm{X}} \sigma_{\mathrm{Y}}}
$$


where E () is the Expected value.

After computations made on our data collected and following the previous formula, we found the results presented in Figures 10,11, 12, 13 and 14. and that evidence the existence of a strong correlation between the set of interactions tools especially for pages $\mathrm{C}, \mathrm{E}$ and $\mathrm{H}$.

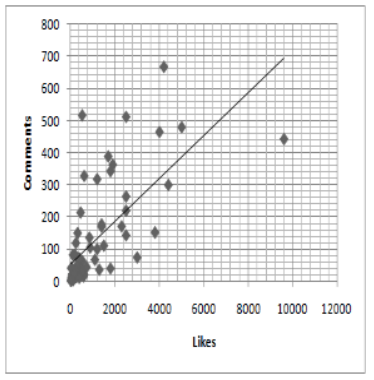

$r=0.6780$

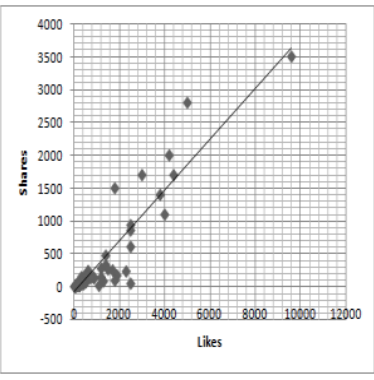

$r=0.9197$

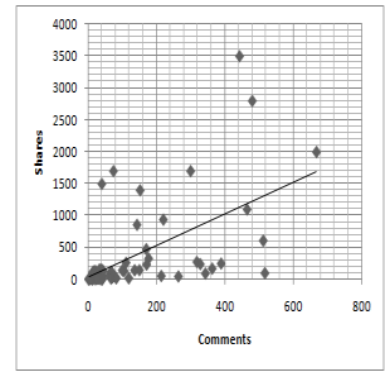

$\mathrm{r}=0.5752$

Fig. 11. Correlation Results for Page E

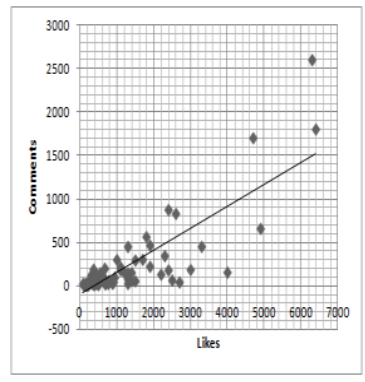

$r=0.8222$

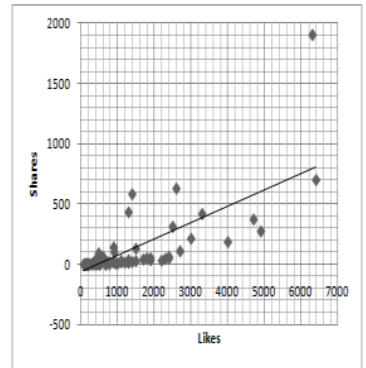

$r=0.7287$

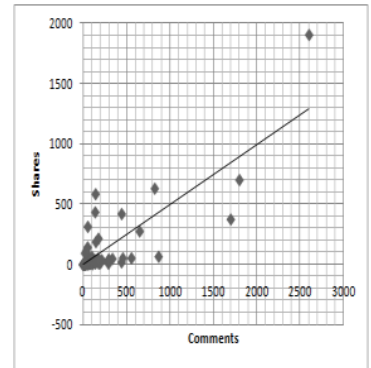

$r=0.8201$

Fig. 12. Correlation Results for Page $\mathrm{H}$ 


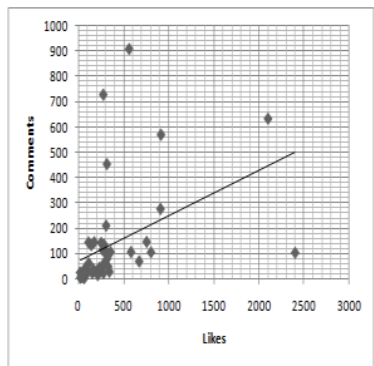

$r=0.4211$

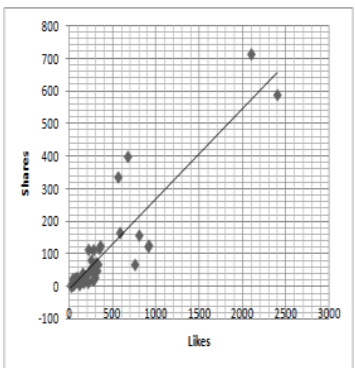

$r=0.9002$

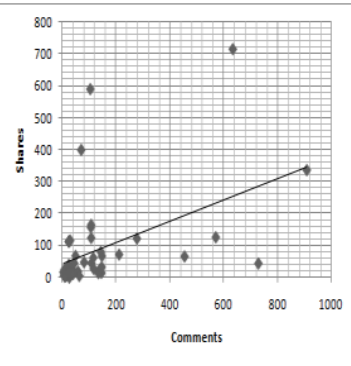

$r=0.4594$

Fig. 13. Correlation Results for Page $L$

Figure 10 shows the correlation results for page B, which clearly states that there is a medium correlation between "Shares" and "Likes". Figure 11 shows the correlation results for page $\mathrm{C}$, which says that there is a strong correlation between the set of interaction tools and less strong in both "Shares" and "Comments". Figure 12 shows the correlation results for page $\mathrm{E}$, which says that there is a strong correlation between the set of interaction tools and less strong in both "Shares" and "Comments".

Figure 13 shows the correlation results for page $\mathrm{H}$, which says that there is a strong correlation between the set of interaction tools "Likes", "Shares" and "Comments". Figure 14 shows the correlation results for page L, which says that there is a medium correlation between the two pair ("Likes", "Comments") and ("Shares", "Comments"). while a strong correlation for the duo ("Shares", "Likes").

\section{Conclusion and Perspectives}

From what we have studied previously, and according to the results found in section 3 , we can say that the all interaction mechanisms usually have a strong link that takes an important correlation score for the duo "Likes" and " shares ". We have also discovered that the media agencies we have just studied through their Facebook page always prefer to publish link-type publications which are of course links towards topics published on their website. The publications as video types come in 2 nd place in terms of sharing and lastly, we find the publications as types images.

We have also noticed that the publications as status type doesn't exist among publications in all of these 5 pages.

Regarding to the most attractive publications type, it appears that there are many links-type publications which are mostly liked and shared, but we cannot confirm this hypothesis because there is no equality in terms of sharing numbers between all types of publications.

It is true that all data extracted from posts published in a single day are not enough to make definite conclusions and peremptory judgments, but we must not ignore the 
mass of these data and the information that can bring with the large number of interactions that presents a subject to be studied by researchers in the field via different approaches. The importance of what we have collected for the five Facebook pages lies in the fact that these are huge numbers, we are talking about 104,066,851 fans, 617,440 likes, 139,614 shares, and 148,488 comments, are the totals of the said pages.

Extracting data was done with a manual way, so as a perspective, our future work is to do it automatically, especially because that we have already identified the set of tags and attributes that bear what we have needs as data. Automatic data extraction will facilitate the collection of all information not only for a single day, but may be spread over several consecutive or sporadic days, or even weeks and months. This next work will surely help us to extract huge data that will allow via Big Data concept, to have good results and to make good decisions.

\section{$5 \quad$ References}

[1] O'Reilly, Tim. (2005). What Is Web 2.0 Design Patterns and Business Models for the Next Generation of Software. Web 2.0 Conference 2005.

[2] Saito K., Kimura M., Ohara K., Motoda H. (2010). Selecting Information Diffusion Models over Social Networks for Behaviour Analysis. European conference, ECML PKDD. P.180195. https://doi.org/10.1007/978-3-642-15939-8 12

[3] Mohcine Kodad, El Miloud Jaara. (2016). Social network: Towards increasing feedbacks and widening the diffusion of information. Journal of Theoretical and Applied Information Technology. 85(1).

[4] Statista. (2018). Most popular social networks worldwide as of April 2018, ranked by number of active users (in millions). [Online], Available at: https://www.statista.com/statistics/272014/global-social-networks-ranked-by-number-of-users, [Accessed 12/06/2018].

[5] Internet World Stats. (2018). World Internet Users Statistics and 2018 World Population Stats. [Online], Available at: https://www.internetworldstats.com/stats.htm, [Accessed $12 / 06 / 2018]$.

[6] Alexa (2018). Top Sites in Morocco. [Online], Available at: https://www.alexa.com/topsites/countries/MA, [Accessed 24/04/2018].

[7] Powell, J. (2009). 33 Million People in the Room: How to Create, Influence, and Run a Successful Business with Social Networking. FT Press.

[8] Wikipedia. (2018). Mark Zuckerberg. [Online], Available at: https://fr.wikipedia.org/wiki/ Mark Zuckerberg, [Accessed 12/06/2018].

[9] Ferran Sabate, Jasmina Berbegal-Mirabent, antonio Canabate, Philipp R. Lebherz. 2014. Factors influencing popularity of branded content in Facebook. European Management Journal. 32. P:1001-1011. https://doi.org/10.1016/j.emj.2014.05.001

[10] Guerraoui, Rachid. (2014). Edge Rank algorithm or filtering according to Facebook. interstices. [Online] Available at: https://interstices.info/lalgorithme-edge-rank-ou-le-filtrageselon-facebook/, [Accessed 12/06/2018].

[11] Kodad, M., Jaara, E.M., Erramdani, M. (2015). SAIF: System for aid to increase feedbacks in social networks with a reliable, credible and transparent way. Proceedings of 2015 International Conference on Cloud Computing Technologies and Applications, CloudTech 2015. https://doi.org/10.1109/cloudtech.2015.7336996 
[12] Shashank Sheshar Singh, Ajay Kumar, Kuldeep Singh, Bhaskar Biswas. (2019). LAPSOIM: A learning-based influence maximization approach for social networks. Applied Soft Computing. 82, 105554. https://doi.org/10.1016/j.asoc.2019.105554

[13] Yaodong Ni. (2017). Sequential seeding to optimize influence diffusion in a social network. Applied Soft Computing, 56, P 730-737. https://doi.org/10.1016/j.asoc.2016.04.025

[14] Junco, R. (2012). In-class multitasking and academic performance. Computers in Human Behavior, 28(6), 2236-2243. https://doi.org/10.1016/j.chb.2012.06.031

[15] Andreas Konstantinidis, Savvas Pericleous, Christoforos Charalambous. (2018). Meta-Lamarckian learning in multi-objective optimization for mobile social network search. Applied Soft Computing. 67, P 70-93. https://doi.org/10.1016/j.asoc.2018.02.026

[16] Valenzuela, S., Park, N., \& Kee, K. F. (2009). Is there social capital in a social network site? Facebook use and college students' life satisfaction, trust, and participation. Journal of Computer-Mediated Communication, 14(4), 875-901. https://doi.org/10.1111/j.10836101.2009.01474.x

[17] Pempek, T. A., Yermolayeva, Y. A., \& Calvert, S. L. (2009). College students' social networking experiences on Facebook. Journal of Applied Developmental Psychology, 30(3), 227-238. https://doi.org/10.1016/j.appdev.2008.12.010

[18] Ellison, N. B., Steinfield, C., \& Lampe, C. (2007). The benefits of Facebook “'friends:” social capital and college students' use of online social network sites. Journal of ComputerMediated Communication, 12(4), 1143-1168. https://doi.org/10.1111/j.1083-6101. 2007.00367.x

[19] Julian Jang-Jaccard, Surya Nepal. (2014). A survey of emerging threats in cybersecurity. Journal of Computer and System Sciences. 80 (2014) 973-933. https://doi.org/10.1016/j. jcss.2014.02.005

[20] Danielle E. Ramo, Theresa M.S. Rodriguez, Kathryn Chavez, Markus J. Sommer ,Judith J. Prochaska. (2014). Facebook recruitment of young adult smokers for a cessation trial: Methods, metrics, and lessons learned. Internet Interventions,1, 58-64 https://doi.org/10. 1016/j.invent.2014.05.001

[21] Back, M. D., Stopfer, J. M., Vazire, S., Gaddis, S., Schmukle, S. C., Egloff, B., et al. (2010). Facebook profiles reflect actual personality, not self-idealization. Psychological Science: A Journal of the American Psychological Society/APS, 21(3), 372-374. https:// doi.org/10.1177/0956797609360756

[22] Kirschner, P. A., \& Karpinski, A. C. (2010). Facebook and academic performance. Computers in Human Behavior, 26, 1237-1245. https://doi.org/10.1016/j.chb.2010.03.024

[23] Kolek, E. A., \& Saunders, D. (2008). Online disclosure: An empirical examination of undergraduate Facebook profiles. NASPA Journal, 45(1), 1-25. https://doi.org/10.2202/ 0027-6014.1905

[24] Pasek, J., More, E., \& Hargittai, E. (2009). Facebook and academic performance. Reconciling a media sensation with data. First Monday, 14(5). https://doi.org/10.5210/fm.v14i5. $\underline{2498}$

[25] Junco, R., \& Cotten, S. R. (2012). No A 4 U: The relationship between multitasking and academic performance. Computers \& Education, 59(2), 505-514. https://doi.org/10.1016/ j.compedu.2011.12.023

[26] Ong, E., Ang, R., Ho, J., Lim, J., \& Goh, D. (2011). Narcissism, extraversion, and adolescent's self-presentation on Facebook. Personality and Individual Differences, 50, 180-185. https://doi.org/10.1016/j.paid.2010.09.022

[27] Ross, C., Orr, E. S., Sisic, M., Arseneault, J. M., Simmering, M. G., \& Orr, R. R. (2009). Personality and motivations associated with Facebook use. Computers in Human Behavior, 25(2), 578-586. https://doi.org/10.1016/j.chb.2008.12.024 
[28] Junco, R. (2012). Too much face and not enough books: The relationship between multiple indices of Facebook use and academic performance. Computers in Human Behavior, 28(1), 187-198. https://doi.org/10.1016/j.chb.2011.08.026

[29] Junco, R. (2012). The relationship between frequency of Facebook use, participation in Facebook activities, and student engagement. Computers \& Education, 58(1), 162-171. https://doi.org/10.1016/j.compedu.2011.08.004

[30] Vitak, J., Zube, P., Smock, A., Carr, C. T., Ellison, N., \& Lampe, C. (2011). It's complicated: Facebook users' political participation in the 2008 election. Cyberpsychology, Behavior and Social Networking, 14(3), 107-114. https://doi.org/10.1089/cyber.2009.0226

[31] T.C. Wong, Hing Kai Chan, Ewelina Lacka. (2017). An ANN-based approach of interpreting user-generated comments from social media. Applied Soft Computing. 52, P 1169-1180. https://doi.org/10.1016/j.asoc.2016.09.011

[32] Mohcine Kodad, El Miloud Jaara. (2016). Towards Increasing Feedbacks and Diffusion of Information in Social Networks. International Journal of Recent Contributions from Engineering, Science \& IT (iJES). 4(1). https://doi.org/10.3991/ijes.v4i1.5477

\section{Author}

Mohcine Kodad is a general chair of the First International Conference on Recent Information Technologies, Fuzzy Systems and Innovation (CINTISI'20) which will be held in Oujda, Morocco. He is working (MATSI Lab) as Professor in the Department of Computer Science in Higher School of Technology of Mohammed First University, Oujda-60000, Morocco. He is a President of East Center of Research, Studies \& Digitalization in Morocco. He obtained his PhD in Informatics from the Science Faculty of Mohammed First University in Morocco. He published his publications in several international journals and international conferences. His research interests are in the areas of Social Network Analysis, Image Processing, SYSML, artificial intelligence and Software Engineering.

Article submitted 2020-06-10. Resubmitted 2020-07-19. Final acceptance 2020-07-22. Final version published as submitted by the authors. 